\title{
Coronal epenthesis and markedness
}

Linda Lombardi

University of Maryland, College Park

To appear in Phonology

\section{Introduction}

It has been argued that Coronal shows a number of properties that suggest it is the unmarked place of articulation. (See especially Paradis and Prunet 1991). One type of evidence for this has been the claim that coronals are common epenthetic segments. However, the same is true of glottals, especially glottal stop. In addition, the empirical support given for epenthetic coronals has been weak, often based on only the single case of Axininca Campa.

Clearly both kinds of segments are relatively unmarked ${ }^{1}$. But in fact their occurrence as epenthetic segments shows different patterns, which have not been previously observed, and which must be accounted for. I will show that we do find cases of coronal epenthesis, but only in special circumstances; they are never the general, purely syllabification-driven epenthetic consonant of a language.

Such a pattern gives every indication of being a classic case of constraint conflict, and I will show that it can be accounted for in Optimality Theory by the use of universally ranked Place feature markedness constraints. I will show how the constraints originally proposed by Prince and Smolensky (1993), 
Smolensky (1993) can be extended to handle both Coronals and glottals appropriately, without the use of the Placeless representations of previous work. It will be argued that coronals appear when additional factors force the use of the more marked Coronal instead of the less marked glottal stop: Coronal, being relatively unmarked, may be the best satisfaction of markedness possible when glottal stop is ruled out for other phonological reasons.

Aside from giving an account of this set of data, this analysis is important because in fact this kind of variable markedness behavior is rather common (see Rice 1996, 2001) for other cases and the conclusion below for some discussion). I show in this paper that close attention to the specifics of the phonological context, together with the OT concept of conflicting constraints, allows a successful approach to one such case of variability.

\section{Laryngeal unmarkedness in Optimality Theory}

Optimality Theory does not presuppose any particular assumptions about representations; its fundamental premises are very general claims about the structure of the grammar (McCarthy 2001:243). Theory-internal arguments for lack of specification are certainly possible within OT (see Lombardi 2001 for an example.) However, markedness constraints are a component of an OT grammar in any case, and representational accounts of markedness effects have to a large extent been abandoned in favor of accounts relying on these constraints 
(McCarthy 2001:128); in fact Prince and Smolensky argue for this approach in the foundational work in OT (Prince and Smolensky 1993:188).

Using the idea of ranked markedness constraints of Prince and Smolensky (1993), Smolensky (1993) shows how epenthesis of unmarked Coronals without underspecification can be achieved by use of the universally ranked hierarchy in (1):

$$
\text { (1) *Lab, *Dor }>>* \text { Cor }
$$

In (2), we see the result when the language has the ranking of other constraints that makes consonant insertion the optimal resolution of hiatus.

(2)

\begin{tabular}{|l|l|l|l|}
\hline$/$ gao/ & $($ Onset, MaxV $)$ & $*$ Lab & $*$ Cor \\
\hline a. gato & & & $*$ \\
\hline b. gabo & & $!^{*}$ & \\
\hline c. ga & $!^{*}$ & & \\
\hline d. ga.o & $!^{*}$ & & \\
\hline
\end{tabular}

As we see in this tableau, once the only surviving candidates are those with some epenthetic consonant, the markedness constraints pick the consonant with the least marked Place. This allows us to analyze the unmarked behavior of the coronal without recourse to underspecification. The /t/ does have Place, and in fact it does violate a Place markedness constraint. But because its markedness 
violation is the lowest ranked one out of all the choices, the candidate with /t/ will be optimal.

This is an important proposal and a profound insight, but there is one small empirical problem, which is that the existence of /t/ as a purely phonologically-driven epenthetic consonant is not particularly well supported by the evidence. Furthermore, although there are cases of coronal epenthesis as I will show below, glottal stop is a common epenthetic segment, and therefore also shows this kind of unmarked behavior.

Lombardi (2001) accounts for the unmarked behavior of glottal stop by extending the Place markedness hierarchy. It is assumed that glottal stop has Pharyngeal place (McCarthy 1994) and the subordinate features in (3) (McCarthy 1989) :

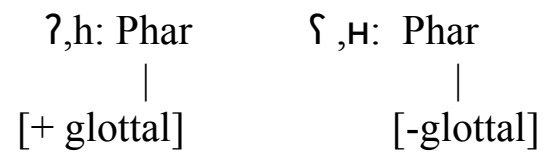

Pharyngeal place is then added to the hierarchy as the least marked Place:

$$
\text { *Dor, }{ }^{*} \text { Lab }>>* \text { Cor }>>* \text { Phar }
$$

The result, as we see in (5), is that / / will be the optimal epenthetic consonant. Its Place markedness violation is even lower than that of the relatively unmarked $/ \mathrm{t} / \mathrm{s}$ 
(5)

\begin{tabular}{|c|l|l|l|}
\hline /gao/ & $($ Onset, MaxV $)$ & $*$ Cor & *Phar \\
\hline a. ga?o & & & $*$ \\
\hline b. gato & & $* !$ & \\
\hline c. ga & $* !$ & & \\
\hline d. ga.o & $* !$ & & \\
\hline
\end{tabular}

The true Pharyngeals such as $/ \mathbb{S}$ are obviously very marked consonants, but my claim is that this must be due to something other than their primary Phar Place. Compare for example English / $\Theta /$, which manages to be highly marked (perhaps due to being nonstrident) despite its unmarked Coronal primary place. Some other feature or feature cooccurrence, rather than Place markedness, must account for the markedness of the interdentals and true Pharyngeals; this is unsurprising since there are obviously dimensions of markedness other than that of primary Place. Following the McCarthy representations above we could assume that in the case of Pharyngeals it is the ranking *[-glottal $]>>*[+$ glottal $]$ makes the true Pharyngeals marked. We see then that true Pharyngeals will not be epenthetic despite their low ranked primary Place²:

(6) 


\begin{tabular}{|c|l|l|l|l|}
\hline$/$ gao/ & $*$ Cor & $*$ Phar & $*$-glottal & $*+$ glottal \\
\hline a. ga?o & & $*$ & & $*$ \\
\hline b. gato & $* !$ & & & \\
\hline c. ga.So & & $*$ & $* !$ & \\
\hline
\end{tabular}

The approach to the behavior of different Places using ranked markedness constraints can account for other aspects of the special behavior of segments with glottal place. As shown in Lombardi (2001), it can be used to achieve neutralization to glottal stop in coda position; it is also shown there that this analysis of neutralization, in contrast to one that assumes Placelessness, allows an explanation of the differences in cross-linguistic patterning of alternations involving Place and those involving Voice. Other work has also shown that this approach can account for other situations where both laryngeals and coronals may show unmarked behavior in different situations. Gafos and Lombardi (1999) demonstrate that by conjoining this markedness hierarchy with a hierarchy of constraints on feature sharing, we can explain cross-linguistic patterns of consonant transparency.

This proposal also solves a long-standing problem with the representation of glottal consonants: They have also been claimed to be Placeless, but then how can they pattern with the guttural natural class in some languages? The only 
solution in previous work has been that [h,?] have different representations in different languages (e.g. Rose 1996). The approach proposed here using ranked markedness constraints allows us to account for the 'unmarked' behavior in transparency and neutralization, while still representing glottals as having a Place feature; thus they can share a Place feature with the other gutturals and behave as part of that natural class.

The work cited shows that this approach allows a uniform representation for glottal consonants cross-linguistically while still accounting for their various types of 'unmarked' behavior. In this paper I will take on the final phonological alternation that is generally cited as evidence for glottal and coronal unmarkedness. I will show that this approach can explain why both coronals and glottals may appear in epenthesis, and also why they appear in slightly different situations. While glottal stop has the most unmarked Place feature, coronals also have relatively unmarked Place features. Thus, when for some reason constraint conflict results in glottal stop being impossible, Coronal will be the next best choice of Place. The correctness of this approach is confirmed by the crosslinguistic facts that I assemble below. As we will see, coronals only occur in epenthesis in certain specific types of situations, while glottal stop is seen in more general situations when pure markedness is permitted to reign over other considerations. 


\section{Epenthesis: coronals vs. glottals}

As we have seen, the revised Place markedness constraints predict glottals will be optimal epenthetic consonants. What about the claims for coronal epenthesis? I will argue that when we examine such cases, ${ }^{3}$ we find that they are restricted: we only see them when factors in addition to Place markedness are active. Constraint conflict will sometimes make it impossible to choose the glottal stop; the next least marked Place, Coronal, will then be seen.

To begin, we first turn to the account of epenthetic glottal stop.

\subsection{Glottal stop}

\subsubsection{Caveats}

Many languages are claimed to have epenthesis of glottal stop, but so many theoretical assumptions underlie the claim that we must reexamine the data for present purposes.

First, many languages have been analyzed as having epenthetic glottal stop purely for the sake of simplifying underlying representations. If a language has no vowel-initial words, but does have glottal stop initial words, it is common to assume that glottal stop is predictable, and therefore should be eliminated from underlying representations. Likewise if there is no contrast between V.V and V.?V, it is common to claim that such sequences are always the result of underlying /VV/ sequences undergoing epenthesis. 
In OT, there not only is no incentive to simplify URs, but in fact we cannot do so, as phonological generalizations cannot be stated on inputs. Because of the assumption of Richness of the Base, in such a language, we must have a ranking which will assure that /VV/ does not surface faithfully, since there are no such sequences. But we cannot exclude the possibility of underlying /V?V/ sequences as well; we cannot force all surface V.?V to be represented as /VV/ underlyingly.

Of course, such a language must have a ranking that neutralizes /VV/ inputs with some /VCV/ sequence (note we are assuming a language that does not present evidence of some other repair such as vowel deletion, or the description would not have posited epenthesis.) And if the analysis in this paper is correct, since I predict that $/ 2 /$ will be the epenthetic consonant when no other considerations intervene, the ranking of such a language will indeed neutralize /VV/ and /V?V/ sequences to V.?V.

Thus even languages that do not have active alternations, I claim, must have the ranking in (5) above that results in glottal stop epenthesis. However, since that reasoning may strike some as somewhat circular, below I will list only languages that show provable active alternations epenthesizing glottal stop.

Second, in languages that resolve hiatus via epenthesis, another common approach is to epenthesize a glide that agrees in features with an adjacent vowel, 
often a high vowel. Assuming some kind of spreading or multiple correspondence, insertion of an agreeing glide may incur fewer markedness violations, so a language may choose this where possible - where a corresponding glide exists. With nonhigh vowels, for most languages a corresponding glide does not exist, and glottal stop will be inserted instead. ${ }^{4}$

I consider glottal stop epenthesis in such languages to be authentic evidence: in phonological environments where spreading is not possible, we see the emergence of the unmarked epenthetic consonant. However, in selecting these cases I have been particularly rigorous about the environments for the glides, due to my assumptions about the features of glottal stop.

For example, in Tamil (Christdas 1988) there is epenthetic [w] with round $[\mathrm{o}, \mathrm{u}],[\mathrm{y}]$ with front $[\mathrm{i}, \mathrm{e}]$, and glottal stop with [a]. We can see that it is productive by alternations:

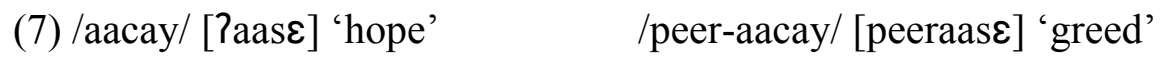
However, my analysis assumes that [?] is Pharyngeal following McCarthy (1989), and it seems likely that the vowel [a] is Pharyngeal as well. So in cases where glottal stop only occurs with [a] it is possible that that is a case of inserting an agreeing segment as well, rather than emergence of the unmarked consonant. So cases where some vowels occur with glides will only be given below if glottal stop is clearly the elsewhere case. ${ }^{5}$ 
Finally, one more point must be addressed about previous analyses of glottal stop epenthesis. In many of these analyses, it has been claimed that glottal stop epenthesis is 'phonetic' or that glottal stop is 'not phonemic', putting epenthesis outside the phonological component. These claims are not a reason for excluding a case as evidence here. Under prior theoretical assumptions, these claims were made as a kind of automatic consequence of the arguments outlined above - that predictable glottal stops could be removed from underlying representations. None of the cases I cite present any other arguments for placing glottal stop in a separate component. Since we no longer assume that the predictability of glottal stop would mean it is absent from all URs, we can also no longer force all non-contrastive glottal stops to wait to appear until later in the derivation. We must in fact account for them in the phonology, which is what this paper will do.

\subsubsection{Glottal stop epenthesis data}

Word-initially in Arabic (McCarthy, pc) there is no contrast between vowel-initial and glottal stop initial words: all words must begin with a consonant. However, alternations show that in some cases these glottal stops are epenthetic. The first forms in both (8)a and (8) b begin with glottal stop, but as we can see in combination with other morphemes, the glottal stop in (8)a is epenthetic and that in $(8) b$ is not. 
(8)a. ?is.maq 'listen' qaa.las.mal 'he said listen!' qaa.la.tis.mal 'she said listen!' b. ?ib.ra 'a needle' qaa.la.7ib.ra 'he said 'a needle", qaa.lat.?ib.ra "she said 'a needle"

In Selayarese (Austronesian, Mithun and Basri 1986), glottal stop is

epenthesized in sequences of identical vowels. Since not all VV sequences are forbidden it is easy to see that the morphemes in question do not have underlying [?], but that it must be productively inserted, as we can see for the two prefixes and roots in (9):

$$
\begin{array}{llll}
\begin{array}{l}
\text { ku-P-urani } \\
\text { ri-urani }
\end{array} & \begin{array}{l}
\text { 'I accompany him' } \\
\text { 'you hon. accompany him' }
\end{array} & \begin{array}{l}
\text { ku-inuyi } \\
\text { ri-?-inuyi }
\end{array} & \begin{array}{r}
\text { 'I drink it' } \\
\text { 'you hon. } \\
\text { drink it' }
\end{array}
\end{array}
$$

This can be contrasted with morphemes that have underlying glottal stop: note especially the form with the same root, 'drink', as used above

$\begin{array}{ll}\text { ta?-ata? } & \text { 'to be roofed' } \\ \text { ta?-entey } & \text { 'to be erected' } \\ \text { ta?-inuy } & \text { 'to be drunk' }\end{array}$

Glottal stop is also inserted initially in the 'intonation unit', so basically words in isolation cannot begin with vowels. We can see that this is productive by alternations as well:

$$
\text { ?innĩ 'this' ?aapa innĩ 'what is this' }
$$

Note also that glottal stop is contrastive within words:

$$
\text { ba?o 'corn dish' pao 'mango' }
$$

In German [?] is optionally inserted before a vowel in what Wiese (1996) 
says is usually described as 'word initially or in syllables with primary stress', and that he analyzes as foot-initial.

(13) Word initial (?)Atem (?)offen

(?)Opa (?)eine

(14) Word internal Chaos $\sim$ Cha(?)otisch

Georg $\sim \mathrm{Ge}(?)$ orgien

Across word boundaries, a vowel-initial syllable can get an onset either by insertion of [?] or by resyllabification ${ }^{6}$ :

(15) Bin ich "am I" [bı.nIç] [bIn.?Iç]

It is impossible to review all the arguments that Hayes and Abad (1989)

give which converge on the conclusion that there is a productive rule of epenthesis in Ilokano. For present purposes I will cite only the most important examples. This case looks at first like Tamil above: nonlow vowels before another vowel turn into the corresponding glide or have a glide inserted depending on the situation, and epenthetic [?] is used after the low vowel [a]. However, additional data ( $\mathrm{p}$ 351) show a situation where both glides and [?] are acceptable with any vowels, with borrowed forms and 'certain forms to which -an and -en are not normally attached.'

(16)a. pag-yoyo?-en cause to play with yoyo pag-yoyow-en

b. trabahw-en work-goal focus trabaho?-en 
trabahow-en

c. pag-basi?-en place where sugar cane wine is made/consumed pag-basiy-en

They say that "native intuitions are insecure concerning which pronunciation is to be preferred' but clearly glottal stop epenthesis is a possibility for some speakers. For our purposes, what is important is that glottal stop insertion between [o-e, i-a] should not even be one of the possibilities if [?] epenthesis in this language is derived by spreading from the prior low vowel.

Czech (Kučera 1961, Spencer 1996) has epenthetic glottal stop wordinitially before a vowel and after a pause, as is common. It seems to also occur at some morpheme boundaries but Kučera's sources disagree on exactly where else it may occur; their disagreement seems to partly result from conflicts about what is prescriptively 'correct'. For our purposes, however, what is most important is that the glottal stop is clearly epenthetic and not underlying. For one thing, its occurrence is optional; also we can see alternations:

$$
\begin{aligned}
& \begin{array}{l}
\text { ?operovat 'to operate' } \\
\text { ?učitel 'teacher' } \\
\text { pod-učitel 'junior teacher' }
\end{array} \\
& \text { In Kisar (Austronesian; Christensen and Christensen 1992) there are no }
\end{aligned}
$$

vowel initial words on the surface, but the language contrasts underlying vowelinitial and glottal stop-initial words, so that there must be productive epenthesis 
word-initially in underlying vowel-initial words. Reduplication treats the two kinds of forms differently in the expected way:

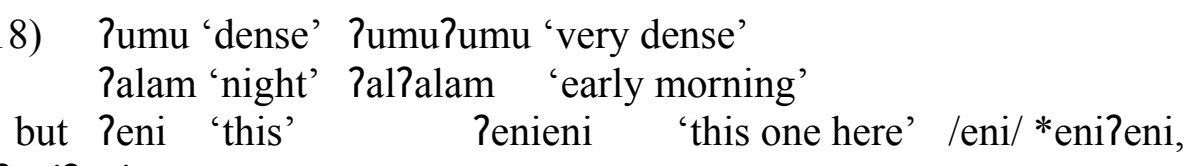

We can also see the contrast between vowel and glottal stop initial words because they take different allomorphs of the first person singular pronoun and the negative morpheme. The first person is [ya?u] with consonant initial words, including underlying glottal stop initial:

$\begin{array}{llll}\text { ya?u karu } & \text { 'I bury' } & \text { ya?u ?omhe } & \text { 'Iwash' } \\ \text { ya?u hi?i } & \text { 'I do' } & \text { ya?u ?elek } & \text { 'I close' }\end{array}$

With underlying vowel initial words, although glottal stop is inserted on the surface, a different monosyllabic form with a copy vowel is used:

$\begin{array}{ll}\text { ya ?amkuru } & \text { 'I sleep' } \\ \text { ye ?esne } & \text { 'I kill' } \\ \text { yo ?omun } & \text { 'I drink' }\end{array}$

Christensen and Christensen analyze this as productive deletion and assimilation but whether this is correct or whether this should instead be seen as allomorphy, the environment is phonological, differentiating underlying glottal stop initial words from those which are underlyingly vowel initial and have glottal stop inserted.

In Malay (Durand 1986, Onn 1980) at stem and suffix boundary, there is 
glide epenthesis with stem final high vowels when followed by a nonidentical vowel, and glottal stop with stem final low vowel or between any two identical vowels. At the stem-prefix boundary there is glottal stop epenthesis only, regardless of vowel; I will provide data from this simpler case only for reasons of space. The first two examples show that the prefix does not have glottal stop underlyingly.

$\begin{array}{ll}\text { /di-pukul/ } & \text { [dipukol] to beat, passive } \\ \text { /di-daki/ } & \text { [didaki] to climb, passive } \\ \text { /di-ikat/ } & \text { [di?ikat] to tie, passive } \\ \text { /di-ankat/ } & \text { [di?ankat] to lift, passive } \\ \text { /di-ukir/ } & \text { [di?uke] to carve, passive }\end{array}$

Koryak (Paleo-Siberian;Kenstowicz 1976) inserts glottal stop wordinitially before a vowel. Forms with consonant-final prefixes, which do not have glottal stop, show that it is not underlying:

$$
\text { ?ajat-ək 'to fall' mal-ajat-ək 'to collapse' }
$$

Indonesian (Cohn and McCarthy 1994) has epenthesis of a an agreeing glide between unlike vowels, but between identical vowels there is productive glottal stop epenthesis: $\begin{array}{lll}\text { /baca-an/ } & {[\text { baca?an }]} & \text { reading } \\ / \text { məmandi-i/ } & {[\text { məmandi?i }]} & \text { give a bath repeatedly }\end{array}$

Gokana and Tunica, both discussed below in section 4, have epenthesis of glottal stop as well as coronal epenthesis. 
Finally, English has epenthesis of glottal stop after pause, and no real vowel-initial words in that environment. But phrase-internally such glottal stops do not normally appear expect under a particularly emphatic pronunciation: eel [?iyl] big eel [bIgiyl] the EEL [thi?íyl]

Thus these morphemes are truly vowel-initial and glottal stop epenthesis is a productive alternation. English also has a tendency to epenthesize glides in hiatus with high vowels, but the environment is not such that it casts doubt on the status of glottal stop as unmarked where it does appear.

Coda glottal stop epenthesis is also found. For example, in Cupeño (Crowhurst 1994) it is used to satisfy a minimal word requirement, as seen in $(25)^{7}:$

$\begin{array}{lll}/ \text { či/ } & \text { či? } & \text { 'gather' } \\ \text { /hu/ } & \text { hu? 'fart' } \\ \text { /kwa/ } & \text { kwa? 'eat' }\end{array}$

As this will be important for purposes of comparison in the next section, I give tableau (26), which shows that the proposed Place constraints give the correct result here as well. 


\begin{tabular}{|l|l|l|l|l|}
\hline$/ \mathrm{hu} /$ & MinWd & *Dor & $*^{*}$ Cor & $*$ Phar \\
\hline hu & $!^{*}$ & & & \\
\hline 吅 & & & & $*$ \\
\hline hut & & & $!^{*}$ & \\
\hline huk & & $!^{*}$ & & \\
\hline
\end{tabular}

The constraint demanding a bimoraic Minimal Word rules out the faithful candidate, so that only candidates with an epenthetic consonant remain for consideration. The Place markedness hierarchy then chooses /hu?/ as optimal, since the *Place violation incurred by the glottal stop is the lowest ranked one. Similar examples of coda glottal epenthesis are Yucatec Maya $/ \mathrm{h} /$ epenthesis in loans to meet requirement that words end in C (Orie and Bricker 1997); Huariapano $/ \mathrm{h} /$ epenthesis to meet requirement that stressed syllables be heavy (Parker 1996); Onondaga utterance-final /h/ epenthesis (Chafe 1970) (the list is not exhaustive).

In all of these cases the epenthetic consonant is chosen purely by Place markedness. However, given that constraints conflict and can be reranked, it is reasonable to expect that such perfect satisfaction of Place markedness will not always be possible for an epenthetic consonant. In the rest of this section, I will show that phonological considerations alone, seen in terms of constraint ranking, can explain the preference for epenthesized coronals in some languages. In the 
next two sections, I will then turn to a discussion of other cases where morphological considerations are involved.

\subsection{Coda epenthesis and sonorance.}

As we have seen above, Place markedness alone predicts that epenthetic consonants would always be glottals, in onset as well as in coda. But as we know that sonorants make good codas (Prince 1983, Zec 1988, Clements 1990), it is not surprising to find that the requirement for a low-marked Place sometimes conflicts with the need to have a sonorant coda. I claim that in such a case we will see coronal epenthesis, since that is the least marked Place a sonorant can have.

Crucial to this analysis is the assumption that glottal stop is an obstruent, which I make following a number of authorities, including Ladefoged (1971), Hyman (1975), Schane (1973), Lass (1976), Bessell (1992), most work in Dependency Phonology (Durand 1986), etc.. (See Bessell 1992 for a summary of claims about the major class features of $[?, \mathrm{~h}])$.

Despite this considerable body of literature, there is an odd persistence of the idea that the glottals [h,?] are glides. The only authority for glottals being glides is Chomsky and Halle (1968), which contradicts the traditional assumption that glottal stop is a stop (see Lass 1976 for references going back to Sweet in the nineteenth century.) As discussed in detail by sources such as Bessell, Lass and 
Ladefoged, Chomsky and Halle's definitions of [cons] and [son], which result in glottals being classified as glides, are problematic.

The definition for sonorance in SPE, as has often been remarked, is odd in that it requires an articulation that would permit spontaneous voicing, but does not require voicing to occur. Ladefoged points out that it is unclear that there is a real phonetic difference between 'spontaneous' and other voicing, and accurately calls this definition 'cumbersome and unmotivated'. Ladefoged suggests a revision which has an acoustic rather than articulatory definition. Stevens and Keyser (1989:93) also classify the laryngeals as [-son]. Bessell (1992: 216-7) shows that in a spectrogram glottal stops are like stops under Ladefoged's and Stevens and Keyser's definitions.

As Lass points out, even under the SPE definition it is rather odd to call glottal stop sonorant, since during the constriction that is the actual articulation of the segment, there is certainly no possibility of spontaneous voicing. But Ladefoged's argument seems more to the point: sonorance is an acoustic property, and there is no evidence to maintain SPE's attempt to define it in articulatory terms.

The definition for [consonantal] in SPE arbitrarily excludes glottal constriction, although the constriction of a glottal stop is certainly as close as that of the oral stops. They give no phonological evidence for the definition, and little 
if any phonological evidence for a natural class of glides including the glottals has surfaced in later work. The one case that is sometimes cited is Kenstowicz and Kisseberth (1979), who analyze Malay nasal spread across glides and glottals . Durand (1986) argues against this case as evidence that glottal are glides, and in any case this one example is entirely insufficient evidence, as we can see by later cross-linguistic work on nasal spread which attempts to explain the whole typology of nasal opacity effects. As shown by Walker (1998), languages vary in what segments are transparent to nasal spread. In many cases glottals allow nasality to spread across them, but in some languages, they block nasal spread, as obstruents do. But in fact Walker shows that languages may treat different subclasses of obstruents differently - subsets defined by voicing and continuance may also behave differently . The fact that nasal may spread through glottals, then, can hardly be invoked as evidence that they are not obstruents. Finally, Hume and Odden (1996) argue that there is in fact no feature [cons] under SPE's definition as including vowels, glides and glottals. They show that there is no evidence for this phonological natural class ${ }^{8}$.

In short, there seems to be no real evidence for Chomsky and Halle's assumption that glottals are glides. They end up in this class as a result of the odder parts of SPE's definitions of the features [cons] and [son] - the arbitrary restriction of [cons] to oral constriction only, and the awkward articulatory 
'spontaneous voicing' definition of [son]. $\mathrm{CH}$ give no real phonological or phonetic evidence for the definitions or natural classes, and they stand alone among prior and later work in proposing these definitions. The persistence of these definitions is purely due to the authorial weight that they carry and not to any weight of evidence.

I therefore assume along with tradition and many other authors that the glottals are stop and fricative, and my analyses can be seen as additional evidence, if any is needed, that this is correct.

I now turn to a detailed examination of the class of cases that show coda epenthesis of a coronal.

\subsubsection{Bristol English}

Bristol English is well known for a rule that inserts /1/ word-finally after a schwa (see for example Hughes and Trudgill 1979, Wells 1982; see Gick 1999 for an alternative gesture-based account ), with the result that words such as "Eva" and "evil" and homophones. This is likely related to the more general English prohibition on word-final short/lax vowels ${ }^{9}$, but for the present purpose I simply assume the constraint in (27).

(27) *ə] $]_{\mathrm{w}}$ : Word-final schwa is prohibited

As we see in (12), the appropriate ranking with Max and Dep (prohibiting deletion and epenthesis respectively; McCarthy and Prince 1995) will ensure that 
epenthesis resolves the violation of the constraint in $(28)^{10}$.

\begin{tabular}{|l|l|l|l|}
\hline /ivə/ & $* \partial]$ & Max & Dep \\
\hline a. ivə & $!^{*}$ & & \\
\hline b. ivəC & & & $*$ \\
\hline c. iv & & $!^{*}$ & \\
\hline
\end{tabular}

I will use (29) to stand for the requirement that sonorants make the best codas. ${ }^{11}$ As we see in (30), if this constraint is high ranked, glottal stop epenthesis will be ruled out. A coronal sonorant will be optimal instead.

(29) SonCoda: Codas should be [+son]

\begin{tabular}{|l|l|l|l|}
\hline /ivə/ & SonCoda & $*$ Cor & *Phar \\
\hline 止ivəl & & $*$ & \\
\hline ivə? & $!^{*}$ & & $*$ \\
\hline
\end{tabular}

Additional constraints still must choose among the different possible coda coronal sonorants. The details of how to state the relevant constraints are beyond the scope of this paper, but let us consider at least the choice between the nasal and nonnasal sonorants, as this will also be important in the next example. The appropriate ranking of some constraints like those in (31) will make the correct 
choice between /1/ and /n/, as in (32).

(31) *NasCoda: Nasal codas are prohibited

*NonnasCoda: Nonnasal codas are prohibited

\begin{tabular}{|l|l|l|}
\hline /ivə/ & $*$ NasCoda & $*$ NonnasCoda \\
\hline r ivəl & & $*$ \\
\hline ivən & $! *$ & \\
\hline
\end{tabular}

\subsubsection{Tunica}

In Tunica we see epenthesis of /n/ phrase finally. According to Haas (1940), phrase-final words are special in various ways including their tone and stress, but what will concern us here is only the requirement that they end in a consonant. A limited number of vowel-final words form their phrase-final forms by vowel deletion, but in most cases the phrase-final form is formed by the insertion of $/ \mathrm{n} /$ :

$\begin{array}{ccc}\text { (33) regular form } & \text { phrase-final form } & \text { (Tone omitted) } \\ \text { hatika } & \text { hatikan } & \text { "again" } \\ \text { sahku } & \text { sahkun } & \text { "one" }\end{array}$

I use (34) as the requirement driving epenthesis:

(34) Phrase-FinalC: Phrases should end in a consonant. This requirement seems likely to be essentially a result of the constraint Final-C proposed by McCarthy (1998; see note 9 above), which requires phonological words to end in a consonant; similar effects may be seen in some of the languages 
with $/ \mathrm{h}$--epenthesis mentioned at the end of section 3.1. As McCarthy shows, due to constraint conflict, the effect of this constraint may emerge only in certain environments; in Tunica, it is only phrase-finally that we see the effect.

(35) shows the interaction resulting in epenthesis:

\begin{tabular}{|l|l|l|l|}
\hline$/$ sahku/ & Phrase-finalC & Max & Dep \\
\hline sahku & $* !$ & & \\
\hline sahkuC & & & $*$ \\
\hline sahk & & $* !$ & \\
\hline
\end{tabular}

Given the ranking of Phrase-Final C and Max and Dep, the optimal candidate must be one with some epenthetic consonant. In the next tableau we then consider the choice among various epenthetic consonants in that position.

The ranking of the nasal coda constraints in (31) must be opposite of what they are in Bristol English, since the nasal consonant is optimal:

\begin{tabular}{|l|l|l|l|l|l|}
\hline /sahku/ & $*$ NonnasCod & $*$ NasalCoda & $*$ Lab & $*$ Cor & $*$ Phar \\
\hline sahku? & $!^{*}$ & & & & $*$ \\
\hline sahkun & & $*$ & & $*$ & \\
\hline sahkum & & $*$ & $! *$ & & \\
\hline
\end{tabular}


Because of the high-ranked requirement for the coda to be Nasal, the least marked Place is not possible, as there are no glottal nasal consonants. Thus, the choice must be made between epenthetic consonants like $/ \mathrm{m} /$ and $/ \mathrm{n} /$. The markedness constraints choose the Coronal /n/ which has the lowest ranked markedness violation of the remaining viable candidates.

Thus, both Bristol English and Tunica confirm the prediction that coronals are only epenthetic when something conflicting is more important than Place markedness. In this case, the conflicting constraints are those that regulate other featural qualities of the coda, sonorance and nasality.

An interesting fact about Tunica is that it also shows epenthetic glottal stop in the construction of these phrase-final forms. Certain kinds of words with final stress must add a prothetic final syllable in order to be able to take epenthetic final /n/. This added syllable has glottal stop onset and a copy vowel, and $/ \mathrm{n} /$ in the coda:

Regular form
ri
ke
ru
?arupo

$\begin{array}{ll}\text { Phrase-final form } & \text { Gloss } \\ \text { ri?in } & \text { house } \\ \text { ke?en } & \text { wasp } \\ \text { ru?un } & \text { hickory } \\ \text { ?arupo?on } & \text { dream }\end{array}$

As we see from the following tableau, this will follow from the ranking already established, since the onset consonant is not subject to the constraints on moraic 
consonants. (*Place marks for the underlying /r/ are omitted.)

\begin{tabular}{|l|l|l|l|l|l|}
\hline$/$ ri/ & $*$ NonnasCod & $*$ NasalCoda & $*$ Lab & $*$ Cor & $*$ Phar \\
\hline ri?i? & $! *$ & & & & $* *$ \\
\hline ri?in & & $*$ & & $*$ & $*$ \\
\hline rinin & & $*$ & & $* * !$ & \\
\hline
\end{tabular}

Thus we see within a single language, even a single form, the different effects of markedness in onset and coda. Because the onset is not subject to a requirement of high sonority, the least marked Place, Phar, is optimal. But in the coda, which must be sonorant, the best we can do is coronal. ${ }^{12}$

\section{Coronal sonorant epenthesis - onsets}

In onset position, sonorants are not preferable; obstruents presumably are because of the steeper sonority cline they give to the syllable. So the explanation for coronals instead of glottals in cases of onset epenthesis must be different from that for coda epenthesis given in the previous section; we do not expect to see a constraint preferring sonorants in this position.

All of the cases of onset coronal sonorant epenthesis that I know of are restricted to particular morphological situations; they are never the general epenthetic consonant of the language. I will not give detailed analyses of these 
cases; the intricacies of how to treat these morphological restrictions in OT is outside the scope of this paper, although in the last subsection I will briefly discuss some analytical issues. However, I will describe the facts for each case and show that they support the claim there is no language where the general, phonologically driven epenthetic consonant is a coronal; in all of them the story is more complicated, confirming the generalization that coronal epenthesis is only seen when something additional to Place markedness is active.

\section{1 Gokana}

In restricted circumstances, Gokana (Hyman 1985, 1982) has epenthesis of the segment Hyman calls underlying /1/. This is realized as [r] intervocalically in an oral context and as $[\mathrm{n}]$ in a nasal context, as seen in the following examples (tone omitted):

a. Second person plural: oo tu-i 'you pl. took' oo zov-ii 'you pl. danced' oo sii-rii 'you pl. caught'

oo gõ-ĩ 'you pl. hid'

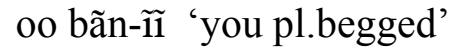
oo nãã-nĩ 'you pl. made'

b. Logophoric:

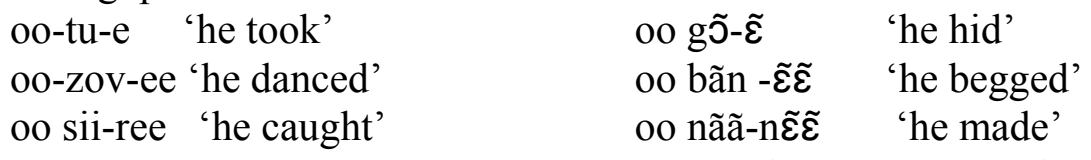

(Hyman 1985:65)

This type of epenthesis is found only with these two suffixes, the second person plural subject and the Logophoric, and under Hyman's analysis has additional 
phonological restrictions as well. There are two restrictions:

One, this type of epenthesis only occurs between two long vowels.

After a short vowel, long vowels shorten instead, as we see from the /II/ suffix in the following:

(40) oo-k $\tilde{\varepsilon} \tilde{\varepsilon}-\tilde{\varepsilon}-\tilde{1} \quad$ 'you pl. woke (it) up' (Hyman 1982:(15b))

Two, this type of epenthesis only occurs within a particular morphological domain. Hyman calls it a "foot," but it is clear that it is a morphological constituent:

(41) Hyman's (33) Gokana "foot" structure:

Root+grade suffix + derivational suffix + inflectional suffix

Object clitics and other morphemes that follow these suffixes are excluded from this structure, which is also the relevant domain for certain tonal phenomena, unlike vowel harmony and nasalization which extend over the whole phonological word. Again, outside this domain there is no epenthesis -- instead we see shortening:

$$
\begin{array}{ll}
\text { bae-div-ee } & \text { 'they hit him' } \\
\text { bae-sii-e } & \text { 'they caught him' }
\end{array}
$$

(Hyman 1982:(9))

Apparently, then, two long vowels in a row are forbidden in all circumstances, but violations of this constraint are resolved in different ways in different situations. What is important for present purposes is that the epenthetic coronal is restricted 
only to a particular morphological domain; it is not the general phonologicallydriven epenthetic consonant of the language. In fact, Gokana also has glottal stop epenthesis occurs word-initially, where only syllable structure is involved and the additional morphological and phonological conditioning of the coronal sonorant epenthesis rule is absent.

\subsection{Japanese}

In the verbal paradigm, Japanese has several endings that have r-initial and vowel-initial variants:

$\begin{array}{lll}\text { (43) C-final stems } & \text { V-final stems } \\ \text { pres. } & \text { das-u 'put out' } & \text { tabe-ru 'eat' } \\ \text { prov. das-eba } & \text { tabe-reba } \\ \text { pass. das-areru } & \text { tabe-rareru }\end{array}$

It is controversial whether this is deletion (Poser 1986, McCawley 1968) or epenthesis (Mester and Ito 1989, de Chene 1985). deChene, the most detailed study arguing for epenthesis, partly bases this on evidence from the results of an experiment using nonsense verbs. De Chene writes a rule that is morphologically restricted: it is stipulated to apply at a verb stem boundary only. We can see this in the following example which has both verb stem and adjective stem boundaries.

$$
\left.\left.\left.\left[\left[\left[[\mathrm{mi}]_{\mathrm{VS}} \text { are }\right]\right]_{\mathrm{VS}} \mathrm{na}\right]\right]_{\mathrm{AS}} \mathrm{i}\right]\right]_{\mathrm{A}} \quad->\quad \text { mirarenai 'won't be seen' }
$$


If this alternation is actually deletion, of course, then it is irrelevant for my purposes; and in fact the number of endings is small enough that it also seems likely that this could simply be allomorphy. But if the controversy is resolved in favor of epenthesis, this case also fits the prediction: the epenthetic coronal is only seen in a restricted situation (onsetless syllables are otherwise permissible).

\subsection{Fula}

Bagemihl (1989): /n/ is a default epenthetic consonant in a language game in

Fula. This game normally reverses the first two consonants in a word:

$$
\begin{aligned}
& \text { saare raase 'concession' } \\
& \text { war raw 'comes' } \\
& \text { ?umara mu?aru a proper name }
\end{aligned}
$$

However, when the first two consonants are identical, the second is replaced by $/ \mathrm{n} /:$

(46) baaba baana 'father'
daada daana mother
jaaje jaane a proper name

This appears to be the only situation where epenthetic /n/ appears in the language. However we want to take into account language games in constructing our theory of phonology, it is clear that this is a highly restricted situation, and thus fits my generalization.

\subsection{Konni}


In Konni (Gur; Northern Ghana; Cahill 1998, 1999, p.c.), [r] is inserted in a situation which is both morphologically and phonologically restricted. In Noun Class 1 only, [r] is inserted between the stem vowel (which shortens) and the plural suffix if the stem vowel is [aa,ひひ, ৩৩] (tone omitted in the following):

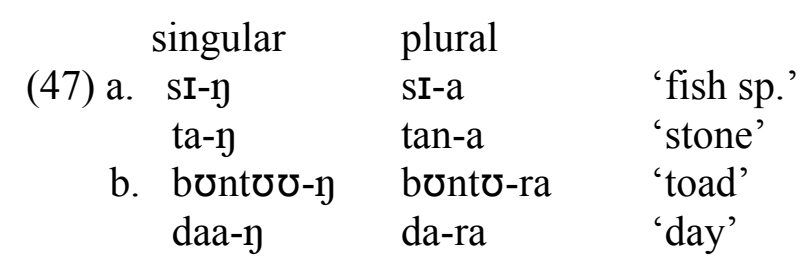

In contrast, the general epenthetic consonant of the language is glottal stop. It is inserted at the ends of utterances and between vowels across a word boundary (Cahill, p.c., 1999).

Obviously a number of phonological factors also come into play in this example. It is not a straightforward case of epenthesis to satisfy Onset, since short-vowel final stems (31a) do not epenthesize. Other long vowels also do not show [r] epenthesis, as Cahill argues, because of the emergent effects of constraints against [r] next to [+ATR] vowels and vowels which are Coronal. Nevertheless, the choice of $[\mathrm{r}]$ as the consonant in those situations where epenthesis does apply is consistent with generalizations in this paper. Glottal stop (and rare [h]) can only occur at word-edge. Thus, although they are the least marked in Place, this higher ranked restriction on their position forces the choice 
of the slightly more marked Coronal, [r], as the epenthetic consonant. ${ }^{13}$

\section{5. /t/ epenthesis}

So far, I have shown that there are languages that have epenthesis of coronal sonorants. Some cases are phonologically driven, due to high ranking of the requirement for codas to be sonorant. Others, where coronal sonorants appear in onsets, seem to be due to factors that are not purely phonological.

However, a few languages do have epenthetic/t/, including Axininca, which is the case usually cited to support the existence of coronal epenthesis. I now turn to these cases. These also show morphological restrictions, although I will also discuss some relevant phonological considerations.

\subsection{Axininca}

Axininca Campa (Payne 1981) has a complicated pattern of epenthesis related to a variety of prosodic morphological requirements, as shown in the OT analysis of McCarthy and Prince (1993). The epenthetic/t/ is always in onset position, and at least part of the motivation for its presence is the Onset constraint. The following examples show some of the simplest cases. (McCarthy and Prince 1993; Payne 1981:108.)

(48) I-N-koma-i inkomati 'he will paddle'
i-N-koma-aa-i inkomataati 'he will paddle again'

Morphological considerations are crucial to where this epenthesis occurs, as 
McCarthy and Prince show in detail. The most straightforward part of the restriction is that this is found only with suffixation, not prefixation; hiatus in prefixation is resolved by deletion. In this sense, it is clear that this case fits in with the earlier cases where coronals are epenthetic only in morphologically restricted cases.

However, there are also some crucial phonological considerations. One central one is the fact that apparently Axininca simply doesn't allow / $/$ at all. This will clearly require it to resort to some other relatively unmarked consonant, roughly as in (49) (where $* ?$ stands for the constraint ruling out glottal stop. $)^{14}$

\begin{tabular}{|l|l|l|l|l|}
\hline /inkoma $+\mathrm{i} /$ & $* ?$ & $*$ Lab & $*$ Cor & $*$ Phar \\
\hline inkoma?i & $!^{*}$ & & & $*$ \\
\hline ๘igkomati & & & $*$ & \\
\hline inkomapi & & $!^{*}$ & & \\
\hline
\end{tabular}

However, Axininca does have /h/, which has the unmarked Phar place.

Something else phonological must still be involved, or we make the incorrect prediction that $/ \mathrm{h} /$ will be epenthetic: 


\begin{tabular}{|l|l|l|l|l|}
\hline /igkoma $+\mathrm{i} /$ & $* ?$ & $*$ Lab & $*$ Cor & $*$ Phar \\
\hline inkoma?i & $! *$ & & & $*$ \\
\hline inkomati & & & $*$ & \\
\hline (ंinkomahi & & & & $*$ \\
\hline
\end{tabular}

This seems likely to have to do with the markedness of different sonority clines for onsets, mentioned at the beginning of the last section. In addition to obstruents being preferable to sonorants as onsets, obstruents of differing sonority must be differentiated as well. In this case, we invoke the requirement that the less sonorous stop is a better onset than the more sonorous fricative. In fact these considerations are necessary in any case, since we will also need to explain how /t/ is chosen over other Coronals, such as /s/. Assume the following constraints to stand for the sonority cline requirements: ${ }^{15}$

(51) Some sonority cline constraints:

*FricV: Prohibits fricative onset

*StopV: Prohibits stop onset

Universal ranking *FricV $>>$ *StopV

*SonV: Prohibits sonorant onset

*ObsV: Prohibits obstruent onset

Universal ranking *Son $\mathrm{V}>>* \mathrm{Obs} \mathrm{V}$

As we see in (52), these constraints will correctly choose /t/ over the other coronals; they will also force the epenthetic consonant to be Coronal rather than less marked Pharyngeal place, since the only available glottal consonant is a 
fricative and so is ruled out by the higher ranked sonority constraint *FricV.

\begin{tabular}{|l|l|l|l|l|}
\hline /inkomai/ & *SonV & *FricV & *Cor & *Phar \\
\hline inkomahi & & $* !$ & & $*$ \\
\hline ijkomasi & & $* !$ & $*$ & \\
\hline inkomali & $* !$ & & $*$ & \\
\hline ifinkomati & & & $*$ & \\
\hline
\end{tabular}

Thus, again we see that a coronal consonant will only be epenthetic when conflicting higher ranked constraints prevent the choice of the glottal consonants with their lower marked Place feature.

\subsection{Amharic}

Broselow (1984) argues that Amharic uses /t/ as a default consonant in several situations.

In one case, $/ \mathrm{t} /$ is argued to be used to fill the last template position in the roots in (a). This is to explain their difference from the roots in (b), which Broselow argues are actually roots with underlying identical consonants, acting identically to the triconsonantal root in (c). Note that not all template positions are obligatory - we see the epenthetic / $t /$ in the gerund and infinitive of (a), but not in the final slot of the perfective.
(a) /fj/ 'consume'
(b) /wdd/ 'like'
(c) /lbs/ 'open' 


$\begin{array}{llll}\text { fäjjä } & \text { wäddädä } & \text { läbbäsä } & \text { perfective } \\ \text { fäjto } & \text { wäddo } & \text { läbso } & \text { gerund } \\ \text { mäfjät } & \text { mäwdäd } & \text { mälbäs } & \text { infiniti }\end{array}$

ve

Broselow also argues for $/ \mathrm{t} /$ epenthesis to explain the variation in the passive-reflexive, which is indicated by [tä] in the perfect, but by gemination of the first root consonant in the infinitive:

(54) perfect: tä-läbbäsä infinitive: mä-lläbäs 'be dressed' (Tigrinya shows the same variation in this prefix, see Kenstowicz 1982.)

Finally, there are certain verbal suffixes that appear as $[\mathrm{u}]$ after a consonant, $[\mathrm{w}]$ after a vowel, but $[\mathrm{t}]$ after $[\mathrm{u}, \mathrm{o}]$. This is driven by a prohibition on a round vowel-[w] sequence in a syllable rime.

$$
\begin{array}{ll}
\text { masc. object clitic: läbsa 'her having dressed' } & \text { läbsa-w 'her having dressed him' } \\
& \text { läbso 'his having dressed' } \\
& \text { läbso-t 'his having dressed him' }
\end{array}
$$

As is clear from the descriptions, these are not cases of syllable-structure-driven epenthesis. Broselow's analysis is that the /t/ occurs in all of these situations because it is the default consonant of the language. However, $/ \mathrm{t} / \mathrm{is}$ not not the general epenthetic consonant of the language. There is optional word-initial/?/ epenthesis (antä ?antä 'you'); in hiatus, either vowels are deleted or glides are inserted depending on the situation (Leslau 1968,1997). 
For the present purpose, it seems clear that these cases all fit into the generalization I propose, as all cases of / $\mathrm{t}$-epenthesis are morphologically specific. Only certain templates demand the /t/ to fill an empty slot, and the other two cases are specific to certain morphemes ${ }^{16}$.

A detailed analysis of the Amharic facts is beyond the scope of this paper; however, a plausible approach might be a ghost consonant associated with certain morphemes. Broselow points out that the epenthetic / $t /$ developed historically from a morpheme; perhaps this morpheme developed into floating features associated with certain morphemes in the current language. If this is the case, as I discuss below in section 6 , we must be cautious in drawing conclusions that markedness is at work in this example at all, since other consonant Places can be involved in such floating features, not just unmarked ones.

\subsection{Odawa}

In Odawa (Ojibwa; Piggott 1990) there is /t/ epenthesis at the boundary between a personal prefix and a stem: (Omitted are the result of additional rules deleting vowels.)

$$
\begin{array}{lll}
\text { /ki-akat-i/ } & \text { kitakači } & \text { 'you are shy' } \\
\text { /ki-osāmikwām-m/ } & \begin{array}{l}
\text { kitosāmkwāmim } \\
\text { /ni-ompass/ }
\end{array} & \text { 'you pl.oversleep' } \\
\text { nitōmpass } & \text { 'my bus' }
\end{array}
$$

In other situations hiatus is resolved by deletion: note the contrast when the same prefix is attached to a different class of nouns, those of inalienable possession 
(57); (some deletion is variable, (58b)):

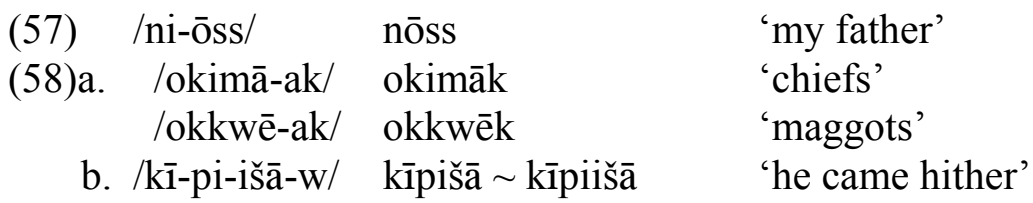

As in most of the cases of coronal epenthesis in onset, then, this is clearly morphologically restricted. Here, as in Amharic, since only a handful of morphemes are involved, a ghost consonant or floating features seems like a possible analysis. The same phenomenon is seen in related Algoniquian languages (Bloomfield 1946) and Plains Cree (Wolfart 1973): prefixes show [t] insertion although hiatus is resolved differently in other situations, and Bloomfield notes that certain stems do not show insertion even with the relevant prefixes.

To sum up, then, we have seen that in all cases where epenthetic /t/ is attested, it is never the general epenthetic consonant of the language.We often see glottal stop epenthesis throughout a language to satisfy purely phonological requirements such as Onset; we do not seem to see similar cases of /t/ epenthesis. All of these cases are restricted morphologically, and as in Axininca may also be the result of additional conflicting phonological constraints. Again, although indepth analysis of the morphological restrictions is outside the scope of this paper, it is clear that these cases do not provide evidence that $/ t /$ is ever used for general 
syllable-driven epenthesis. ${ }^{17}$

\section{Morphological specificity and relevance to markedness}

I have argued that cases of coronal epenthesis in coda can be analyzed purely phonologically, as the result of the attempt to best satisfy both Place markedness and sonorance markedness in codas: the least marked Place that will also satisfy the sonorance requirement is coronal, even though this is not the least marked possible Place in general. In contrast, cases of coronal epenthesis in onset, although sometimes also involving some additional phonological considerations (as in Axininca), have been shown to always involve crucial reference to morphology.

I will not given specific analyses of how we are to analyze the restriction to morphological contexts in each of these cases, as the details of these are outside the scope of my main argument. But it is important to give some consideration to this question, because it bears on the question of whether certain of these examples are relevant evidence regarding markedness at all.

Current work in OT generally limits processes to specific morphological contexts using Faithfulness constraints relativized to morphological domains, following McCarthy and Prince's (1995) account of processes specific to reduplication. For example, consider a hypothetical case resembling Axininca and Odawa. Assume that for prefixes, [t] is inserted to break up vowels; in other 
situations, the second vowel deletes. One possibility is that this prefix-stem interaction is specific to a particular vocabulary class. A constraint $\operatorname{Max}_{\mathrm{p}} \mathrm{V}$, which by definition applies only in prefixation, is higher ranked than DepC. The result is that epenthesis is optimal:

\begin{tabular}{|c|l|l|l|}
\hline$/$ pi+opigi/ & Onset & $\operatorname{Max}_{\mathrm{p}} \mathrm{V}$ & DepC \\
\hline piopigi & $* !$ & & \\
\hline piCopigi & & & $*$ \\
\hline popigi & & $* !$ & \\
\hline
\end{tabular}

The ranked markedness constraints that we have seen above would then determine the nature of the epenthetic consonant. Outside of prefixation, however, only general MaxV will be relevant. If this is ranked below DepC, we will find that deletion is optimal in cases other than prefixation:

\begin{tabular}{|c|l|l|l|l|}
\hline /opigi $+\mathrm{a} /$ & Onset & $\operatorname{Max}_{\mathrm{p}} \mathrm{V}$ & $\mathrm{DepC}$ & $\operatorname{MaxV}$ \\
\hline opigia & $* !$ & & & \\
\hline
\end{tabular}




\begin{tabular}{|l|l|l|l|l|}
\hline opigiCa & & & $* !$ & \\
\hline เ opiga & & & & $*$ \\
\hline
\end{tabular}

Another possibility would be to argue there was something more like a level difference, translated into OT terms via the use of output-output faithfulness constraints following Benua (1997). Assume here that suffixes trigger an OO faithfulness relation, but prefixes are subject only to IO faithfulness. With the following ranking, consonant epenthesis will be optimal in prefixation:

\begin{tabular}{|c|l|l|l|}
\hline$/$ pi+opigi/ & Onset & Max IO V & Dep IO C \\
\hline piopigi & $* !$ & & \\
\hline piCopigi & & & $*$ \\
\hline popigi & & $* !$ & \\
\hline
\end{tabular}

However, in suffixation, a higher ranked DepOO constraint comes into play, which compares the affixed version to the unaffixed root [opigi]. (I omit DepOOC marks for the suffix itself, which are the same for all candidates.) Now the second candidate, with epenthesis, fails on the highest ranked constraint, since it contains an extra consonant with no correspondent in the unaffixed form. The violation of MaxIO- $\mathrm{V}$ in the third candidate is thus not fatal in this tableau, and the candidate with deletion wins: 


\begin{tabular}{|l|l|l|l|l|}
\hline /opigi+a/ & Dep OO C & Onset & MaxIOV & DepIOC \\
\hline opigia & & $* !$ & & \\
\hline opigiCa & $* !$ & & & $*$ \\
\hline ropiga & & & $*$ & \\
\hline
\end{tabular}

Approaches like these may be relevant for some of the cases cited; obviously more research into their phonology-morphology interactions would be neccessary to determine this. However, another possible approach, which seems plausible for many of the examples, is a representational one: the relevant morpheme may contain a ghost consonant. In Japanese and Gokana, only a couple of morphemes are involved; in Konni it is only one ${ }^{18}$, and in Fula, we could be seeing a consonant morpheme associated with the language game.

If large class of morphemes is involved, a more general analysis seems to be preferable. If all prefixes undergo a certain process, it would seem suspicious that they all happen to end with the same ghost consonant underlyingly. In such a case, it is arguably better to assume that prefixes define a vocabulary class that is affected by a relativized Faith constraint like the ones cited above. Thus cases like Japanese, where all verb suffixes are affected, and for Axininca, where all suffixes are affected, seem to call for this type of more general analysis. ${ }^{19}$ 
But what if only one or two morphemes are affected? There is no formal obstacle to relativizing Faithfulness to a specific morpheme; this is necessary, for example, to specify the shape of a particular reduplicative affix. So we could analyze cases like for example Gokana in the same way.

However, some caution is called for when we use this type of case as evidence for the behavior of markedness constraints. This is because we do also still need to recognize the existence of morphemes that come by their specific phonology for representational reasons. Zoll $(1996,2001)$ provides a survey of ghost consonants cross-linguistically and their OT analysis. An important aspect of her survey for the present purposes is that the set of segments that can be ghosts is not restricted to segments with unmarked Places. For example, Armenian and Wolof are both argued to have ghost /k/, and French and Twi, ghost $/ \mathrm{p} /$. As we see in the following examples of the well known phenomenon in French, certain adjectives end in a latent consonant that only appears before a glide or vowel. This is not epenthesis because the choice of consonant is phonologically unpredictable, depending on the particular adjective, and it cannot be deletion because such deletion is not general in the language (Zoll 1996:27).

$$
\begin{aligned}
& \text { [trop] aimé 'too much loved'] [tro] détesté 'too much hated' } \\
& \text { [pətit] étang 'small lake' [pəti] chien 'small dog' }
\end{aligned}
$$

Zoll shows that these latent segments must be represented with underlying Place 
features to distinguish them from one another in the same language. And clearly, since they do not have predictable or unmarked Places, the ghost segments cannot be coming by their surface Place via markedness constraints.

If any of the cases I discuss above turn out to be correctly analyzed as ghost consonants, they are not epenthetic segments at all, and thus are irrelevant to any discussion about Place markedness. Zoll does argue that some of the coronal ghost segments, in French for example, do not have underlying Place, and get Place via markedness. But in fact the other French coronals, the obstruents, are represented with Place features in her analysis. The fact that it is possible for ghost segments to have underlying, marked Places means that we cannot assume that just because a ghost is Coronal (or glottal, for that matter) that it gets Place via markedness. ${ }^{20}$

Thus, if the cases cited are ghosts, it could be purely accidental that they are Coronal. Absent a full analysis of each of these cases, it cannot be assumed that their Place is due to markedness considerations at all. Caution must be used in claiming that any of them are relevant to the question of the Place of epenthetic segments, as they may be neither epenthetic nor underlyingly Placeless.

In sum, then, of the cases cited in this paper, only those of coda sonorant epenthesis, in section 3.2, are clear evidence for the markedness of Place. They are all phonological phenomena. As I have shown, the analysis I propose, using 
ranked Markedness constraints, can account for these cases, as well as for the fact that glottal stop is the more general epenthetic consonant cross-linguistically: Glottal stop has the least marked Place, but conflicting requirements may force the choice of slightly more marked, but still relatively unmarked, Coronal.

In contrast, the examples in sections 4 and 5 are not of purely phonological phenomena; they all show additional morphological conditioning. Many of these have been used in the past to argue for Coronal underspecification. But as I have argued in this section, more careful attention needs to be given to the context of apparent epenthesis rules before asserting that they are relevant to markedness. They may well be - they may have an analysis like that in (43-46) above, with markedness constraint choosing the Place of the inserted consonant. But they may be ghost consonants with underlying Coronal place - and thus totally irrelevant as evidence regarding markedness, a fact that has been insufficiently noted in past literature on this topic.

\section{Conclusion}

On the basis of evidence from epenthesis, neutralization, and transparency here and in previous work, I have argued that the Place markedness hierarchy of Prince and Smolensky (1993), Smolensky (1993) should be modified to include Pharyngeal as the least marked place. This will give glottal stop as the optimal epenthetic consonant, all things being equal. However, all things aren't always 
equal: constraints conflict, so it may not always be possible to perfectly satisfy the markedness constraints. In such cases a coronal may be chosen as epenthetic, since coronals still have a relatively unmarked Place. As evidence for the claim that coronals are only chosen for epenthesis in such cases of constraint conflict, I have shown that coronal epenthesis is always somehow restricted. In coda, coronal epenthesis may occur due to the phonological preference for sonorant codas. In onset we see that there are also always additional restrictions, usually morphological, on coronal epenthesis. The coronal is never the general phonological epenthetic onset in the languages cited, many of which also have glottal stop epenthesis outside the specific situation where a coronal is required. An important conclusion of this paper is that we must be cautious in what we consider to be arguments for markedness. Some of the cases cited are analyzed as clearly epenthetic consonants that get their Place and sonority specifications via markedness constraints. But as pointed out in section 6 some of the cases of apparent epenthesis are so restricted that it may not be correct to analyze them as epenthesis at all: they may be underlyingly ghost consonants, which could have any Place, including Coronal, but which do not provide evidence for the markedness of their features.

The analysis in this paper has important implications for future research in markedness relations. OT allows us to formalize the fact that markedness is 
relative and that there is more than one dimension of markedness. This is clearly necessary because the facts show that there is variability in what is the 'unmarked' segments. I have argued that in the case of epenthesis, this variability is not random; careful analysis shows that interacting facts about position, inventory, etc. in a given language can explain why the least marked Place is not chosen.

Other cases are ripe for reanalysis in these terms. Another case which shows similarities in vowel epenthesis (Lombardi 2002, Rose 1993). The variability in vowel epenthesis is greater than that of consonant epenthesis, but it also is not random variation. For example schwa is a frequent epenthetic vowel, and has often been analyzed as featureless in consequence. This would predict it to be epenthetic in any language that allowed surface schwa in its system. But in fact, while schwa is clearly relatively unmarked by the evidence of its appearance in epenthesis and reduction, in fact where the vowel system contains [i]], it will be epenthetic in preference to schwa. This also looks like a pattern where we need relative markedness rankings, interacting with other constraints, to derive the least marked segment possible given other conflicting requirements.

Another example of such markedness variation is the pattern (mentioned in note 9) described by Trigo (1988), (see also Rice 1996) where the unmarked nasal in coda position often seems to be dorsal. Comparing this to some of the 
facts discussed in this paper we can see that the unmarked coda nasal seems to be sometimes Dorsal and sometimes Coronal. Since nasals cannot have glottal Place, the particular Places involved are different, but the nasal facts are similar to those discussed herein in that there seem to be two relatively unmarked Places for coda nasals. The analysis in this paper suggests that careful examination of these cases in constraint-conflict terms may reveal reasons for this variability.

Additional cases of Place variability in markedness can be found in the work of Rice (e.g. Rice 1996), who goes beyond epenthesis to discuss facts from other types of phonological alternation that seem to bear on markedness. These additional alternations, for example asymmetries in behavior in assimilation (see Paradis and Prunet 1991 also), remain as future challenges.

\section{Bibliography}

Bagemihl, B. 1989. The crossing constraint and 'backwards languages'. NLLT 7:481-549.

Baković, Eric. 1999. Deletion, insertion and symmetrical identity. Ms., Harvard University.

Bender, M. and H. Fulass 1978. Amharic verb morphology. African Studies Center, Michigan State University.

Benua, Laura . 1997. Transderivational identity: phonological relations between words. PhD dissertation, University of Massachusetts, Amherst.

Bernhardt, Barbara and Joseph Paul Stemberger. 1998. Handbook of phonological development from the perspective of constraint-based linear phonology. Academic Press, San Diego.

Bessell, Nicola. 1992. Towards a phonetic and phonological typology of post- velar articulation. University of British Columbia dissertation.

Bloomfield, 1946. Algonquian. In Hoijer, Harry ed., Linguistic structures of native America. 
Booij, Geert. 1996. Cliticization as prosodic integration: the case of Dutch. The Linguistic Review 13, 219-242.

Booij, Geert. 1995. The phonology of Dutch. Clarendon Press, Oxford.

Broselow, E. 1984. Default consonants in Amharic morphology. Papers from the MIT workshop in morphology. MITWPL 7, 15 - 32.

Cahill, Michael. 1998. Tonal polarity in Konni nouns: an Optimal Theoretical account. Ohio State University Working Papers in Linguistics 51, 1958.

Cahill, Michael. 1999. Aspects of the phonology and morphology of Konni. PhD dissertation, Ohio State University.

Chafe, Wallace L. 1970. A sematically based sketch of Onondaga. Supplement to IJAL 36.2.

Chomsky, Noam and Morris Halle. The sound pattern of English. Harper and Row., New York.

Christensen, John and Sylvia. 1992. Kisar phonology. In Burquest, Donald A. and Wyn D. Laidig, eds., Phonological studies in Four Languages of Maluku. SIL, University of Texas at Arlington.

Christdas, Prathima. 1988. The phonology and morphology of Tamil. Cornell $\mathrm{PhD}$.

Clements, G.N. 1990. The role of the sonority cycle in core syllabification. In Papers in Laboratory Phonology I, eds. John Kingston and Mary Beckman, 283-33. Cambridge University Press.

Cohn, Abby and John J. McCarthy. 1994. Alignment and parallelism in Indonesian phonology. Ms, Cornell and UMass Amherst.

Crowhurst, Megan. 1994. Foot extrametricality and template mapping in Cupeño. NLLT 12:177-201.

de Chene, Brent. 1985. r-epenthesis and the Japanese verb. Papers in Japanese Linguistics.

Delattre, P. 1971. Pharyngeal features in the consonants of Arabic, German, Spanish, French and American English. Phonetica 23:129-155.

Durand, Jacques. 1986. On the phonological status of glides: the evidence from Malay. In J. Anderson and J. Durand eds., Explorations in Dependency Phonology. Dordrecht: Foris. 79-107.

Firth, J.R. 1948. Sounds and prosodies. In F.R.Palmer (1970) ed., Prosodic Analysis. Oxford University Press.

Gafos, Diamandis and Linda Lombardi. 1999. Constraint transparency and vowel echo. Proceedings of NELS 29, v.2 81-95. GLSA, Amherst MA.

Gick, Bryan. 1999. A gesture-based account of intrusive consonants in English. Phonology 16 29-54. 
Gnanadesikan, Amalia. 1997. Phonology with ternary scales. PhD dissertation, University of Massachusetts at Amherst.

Haas, Mary R. 1940. Tunica. Extract from Handbook of American Indian Languages vol.IV.

Hayes, Bruce and May Abad. 1989. Reduplication and syllabification in Ilokano. Lingua 77:331-74.

Hironymous, Patricia. 1999. Selection of the Optimal Syllable in an Alignment-based Theory of Sonority. PhD dissertation, University of Maryland, College Park.

Hudson, G. 1982. Review of Bender and Fulass, Amharic Verb Morphology, Afroasiatic Linguistics 8, 3-9

Hughes, A. and P. Trudgill. 1979. English accents and dialect. Edward Arnold, London.

Hume, Elizabeth and David Odden. 1996. Reconsidering [consonantal]. Phonology 13 345-76

Hyman, Larry. 1975. Phonological theory and analysis. Holt Rinehart Winston, New York.

Hyman, Larry. 1982. The representation of length in Gokana. In Proceedings of the first annual West Coast Conference on Formal Linguistics. 198-206. Stanford University.

Hyman, Larry. 1985. A theory of phonological weight. Foris, Dordrecht. Ito, Junko, Armin Mester and Jaye Padgett. Licensing and underspecification in Optimality Theory. LI 26 571-614.

Kager, Rene. 1999. Optimality Theory. Cambridge University Press.

Kenstowicz, M. 1982. Gemination and spirantization in Tigrinya. Studies in the linguistic sciences 12: 103-122.

Kenstowicz, Micheal. 1976. Some rules of Koryak phonology. Studies in the Linguistic Sciences 6 22-37

Kenstowicz, Michael and Charles Kisseberth. 1979. Generative phonology: description and theory.

Kučera, Henry. 1961. The phonology of Czech. Mouton.

Ladefoged, P. 1971. Preliminaries to linguistic phonetics. University of Chicago press.

Lass, R. 1976. On the phonological characterization of [?] and [h] . In R. Lass,ed., English phonology and phonological theory. Cambridge University Press. Berkeley.

Leslau, W. 1968. Amharic textbook. University of California Press,

Leslau, W. 1997. Amharic phonology. In AlanS. Kaye, ed., Phonologies 
of Asia and Africa. Winona Lake, Indiana: Eisenbrauns.

Lombardi, Linda. 2001. Why Place and Voice are different: constraintspecific alternations in Optimality Theory. In Lombardi, L. ed. Segmental phonology in Optimality Theory: Constraints and Representations. Cambridge University Press.

Lombardi, Linda. 2002. Vowel epenthesis and markedness constraints. Ms, University of Maryland College Park.

McCarthy, John J. and Alan Prince. 1990. Prosodic morphology and templatic morphology. Perspectives on Arabic Linguistics II. Mushira Eid and John McCarthy, eds. John Benjamins.

McCarthy, John J. 1989. Guttural phonology. Ms., University of Massachusetts, Amherst.

McCarthy, John J. 1993. The parallel advantage: containment, consistency, and alignment. Paper presented at Rutgers Optimality Workshop.

McCarthy, John J. 1994. The phonetics and phonology of Semitic pharyngeals. Keating, P. ed., Phonological structure and phonetic form: Papers in Laboratory Phonology III. Cambridge University Press.

McCarthy, John J. 1993. A case of surface constraint violation. Canadian Journal of Linguistics 38:169-195.

McCarthy, John J. 1998. Constraints on word edges. Talk presented at Johns Hopkins.

McCarthy, John J. 2001. A thematic guide to Optimality Theory. Cambridge University Press.

McCarthy, John J. and Alan Prince. 1993. Prosodic Morphology I: Constraint Interaction and Satisfaction . Ms., University of Massachusetts, Amherst and Rutgers University.

McCarthy, John J. and Alan Prince. 1995. Faithfulness and reduplicative identity. University of Massachusetts Occasional Papers 18. GSLA, Amherst MA.

McCarthy, John J. and Alison Taub. 1992. Review of Paradis and Prunet. Phonology 9: 363-370.

McCawley, James D. 1968. The phonological component of a grammar of Japanese. Univ of Chicago Press.

Mester, R.A. and Junko Ito. 1989. Feature predictability and underspecification: Palatal prosody in Japanese mimetics. Language 65, 259-93.

Mills, Roger. 1975. Proto South Sulawesi and Proto Austronesian Phonology. PhD dissertation, University of Michigan.

Mithun, Marianne and Hasan Basri. 1986. The phonology of Selayarese. Oceanic Linguistics 25:210-254. 
Moren, Bruce. 1999. Distinctiveness, coercion and sonority: a unified theory of weight. PhD dissertation, University of Maryland, College Park.

Onn, Farid M. 1980 Aspects of Malay phonology and morphology. Universiti Kebangsaan Malaysia, Bangi.

Orgun, Cemil Orhan. 2001. English r-insertion in Optimality Theory. NLLT 19 737-749.

Orie, Olanike-Ola and Victoria R. Bricker. 1997. Laryngeal contrasts in Yucatec Maya. Paper presented at LAGB Conference, University of Edinburgh.

Ortmann, Albert. 1998.Consonant epenthesis: its distribution and phonological specification. Ms.

Paradis, Carole and Jean-Francois Prunet. 1991. Phonetics and phonology 2: The special status of coronals: internal and external evidence. New York: Academic Press.

Parker, Steve. 1996. Coda epenthesis in Huariapano. Ms., University of Massachusetts at Amherst.

Payne, David L. 1981. The phonology and morphology of Axininca Campa. Summer Institute of Linguistics, University of Texas at Austin.

Piggott, Glyne L. 1980. Aspects of Odawa morphophonemics. Garland.

Poser, William 1986. Japanese evidence bearing on the compensatory lengthening controversy. In E. Sezer and L. Wetzels, eds., Studies in Compensatory Lengthening. Foris. 167-87.

Prince, Alan and Paul Smolensky. 1993. Optimality theory: Constraint interaction in generative grammar . Ms., Rutgers University and Johns Hopkins.

Prince, Alan. 1983. Relating to the grid. LI 14 19-100.

Rice, Keren. 1996. Default variability: the coronal-velar relationship. NLLT 14 493-543.

Rice, Keren. 2001. Featural markedness in phonology:variation. Invited state of the article. GLOT. 4.7 3-6, 4.8 3-7.

Robins, R.H. 1953. The phonology of the nasalized verbal forms in Sundanese. BSOAS 15: 138-45.

Rose, Sharon. 1996. Variable laryngeals and vowel lowering. Phonology 13.

Rose, Sharon. 1993. Coronality and vocalic underspecification. Toronto Working Papers in Linguistics 12. 155-177.

Rosenthall, Sam. 1994. Vowel/glide alternations in a theory of constraint interaction. PhD dissertation, UMass Amherst.

Schane, Sanford A. 1973. Generative phonology. New York:PrenticeHall.

Smolensky, Paul. 1993. Harmony, markedness and phonological activity. 
Paper presented at Rutgers Optimality Workshop and revised handout.

Spencer, Andrew. Phonology: theory and description. Blackwell.

Stevens, Kenneth N. and Samuel Jay Keyser. 1989. Primary features and their enhancement in consonants. Language 65: 81-106.

Trigo Ferre, Lorenza Rosario. 1988. On the phonological behavior and derivation of nasal glides. MIT Dissertation.

Unseth, P. 2002. Bi-Consonantal reduplication in Amharic and EthioSemitic. PhD dissertation, University of Texas at Arlington.

Walker, Rachel. 1998. Nasalization, neutral segments, and opacity effects. Phd dissertation, UC Santa Cruz.

Wells, J.C. 1982. Accents of English v.2, the British Isles. Cambridge University Press.

Wiese, Richard. 1996. The Phonology of German. Oxford University Press.

Wolfart, H. Christoph. 1973. Plains Cree: a grammatical study. Philadelphia: American Philosophical Society.

Yip, Moira. 1992. Sonorant vs. obstruent codas: a prosodic distinction. Ms., University of California at Irvine.

Zec, Draga. 1988. Sonority constraints on syllable structure. PhD dissertation, Stanford Unversity.

Zoll, Cheryl. 1996. Parsing below the segment in a constraint based framework. PhD dissertation, University of California, Berkeley

Zoll, Cheryl. 2001. Constraints and representations in subsegmental phonology. In Lombardi, L. ed. Segmental phonology in Optimality Theory: Constraints and Representations. Cambridge University Press.

Notes

I would like to thank audiences at UMass Amherst, Rutgers, Johns Hopkins, and the 1997 Maryland Mayfest/Hopkins OT workshop for comments on earlier versions of this work, and to them and Keren Rice for directing me to some of the data. Thanks also to Diamandis Gafos, Paul Smolensky and especially John McCarthy, to Micheal Cahill and Pete Unseth for discussion of some of the data, and to the reviewers at Phonology. The usual disclaimers apply; also deepest apologies to anyone else I've forgotten.

1. Note that I do not use 'markedness' in this paper in the restricted sense of implicational relations - if $\mathrm{X}$ exists in a sound system then $\mathrm{Y}$ must also and $\mathrm{Y}$ is therefore unmarked. Recent 
work in phonology considers this to be only one possible type of evidence for markedness relations: see for instance the work on coronals which cites transparency and assimilation asymmetries, as well as epenthesis, as phenomena which should be accounted for by any treatment of markedness, in addition to the traditional frequency and neutralization criteria. OT work on the emergence of the unmarked has revealed additional types of cases as well. (See note 14 for related discussion). See McCarthy 2001 for discussion of the technical meaning of markedness in OT and its relationship to traditional notions of the term. McCarthy notes that relative frequency is not evidence for markedness constraints in OT (also cf. Kager 1999:11). McCarthy and Taub 1992, under earlier theoretical assumptions, discuss the differences between frequency and other types of evidence for markedness.

2. A reviewer asks whether this predicts that other Pharyngeals could be epenthetic if the language lacked laryngeals. While this seems intuitively unlikely, in fact it is very difficult to test, given that languages with pharyngeals but no laryngeals are at least extremely rare and possibly nonexistent. If it turns out that we need to exclude this possibility, we would need to assume that *-glottal is at least higher than *Cor, which seems reasonable, although it cannot be proven from the available data. Further research is necessary on the possible interactions and rankings of major and minor Place markedness, which has not been addressed in the literature.

3.A additional case of coronal sonorant epenthesis that I will not treat here is seen in the Boston dialect first analyzed in OT terms by McCarthy (1993). This case involves a complicated interaction of $[\mathrm{r}]$ epenthesis and $[\mathrm{r}]$ deletion that has so far resisted a full explanation for reasons mostly unrelated to the choice of consonant. See Gick (1999) for a gestural account, Orgun (2001) for a Sympathy-based account relying on sonority, and Bakovic (1999) for an analysis based partly on the suggestion of Gnanadesikan (1997) that [r] is a pharyngealized glide agreeing with the low vowel context; the xrays of Delattre (1971) show that English [r] is pharyngealized. For the present purpose, I only note that this case conforms to my generalization in that $[\mathrm{r}]$ is not the general epenthetic consonant of the language and its behavior clearly involves the interaction of many factors in addition to markedness; Place markedness may not be involved at all, if [r] gets Place from the adjoining vowel like other epenthetic glides in English.

4. See Rosenthall 1994 for one OT implementation of the difference. He assumes the Parse/Fill model of faithfulness, in which the phonology is not responsible for the particular epenthetic segment, but his triggering constraints could straightforwardly be adopted into a Correspondence-based analysis in which the constraints in (5) choose glottal stop. 
5. I should emphasize that I am not arguing that feature agreement is the correct analysis of those cases where glottal stop occurs with [a] only. I know of no analyses in the literature that assume that glottal stop is ever the product of spreading. The arguments (below) that glottal stop is not a glide seem to make such an analysis less likely, since it seems probable that vowels are more able to share features with glides than with obstruents (see Ito, Mester and Padgett 1995 for related discussion). I am merely excluding these cases to be as rigorous as possible about the evidence, since an alternate analysis of those cases is at least conceivable under my assumptions about features. If that alternative analysis is indeed incorrect we could add many more cases of productive glottal stop epenthesis to the data.

6. Dutch (Booij 1995: 65-6) is similar in its environment for epenthesis. However by the criteria outlined above regarding the environment for glides, we can't be positive glottal stop is a case of emergence of unmarked. Glottal stop is only inserted after [a]. If the first vowel of the cluster is schwa, it is deleted; after all other vowels including mid vowels, an agreeing glide is epenthetic.

7. Evidence that these are underlyingly vowel-final comes from the well-studied Habilitative form, in which consonant-final stems map to a template ([čal] -> [ča?a?al] 'husk') but vowel final stems undergo no changes: the habilitative of [?ayu] is [?ayu] 'want'. The habilitative corresponding to [či?] is [či?], thus it is showing the vowel-final pattern.

8. They also renanalyze the nasal spread effects, although under the assumption that the glottals are not obstruents.

9. See McCarthy 1993 for more discussion of related facts in the Boston dialect of English. McCarthy observes that the only non-diphthongal nuclei that can occur word-finally in English are $[\mathrm{a}, ə, 0]$, and after those vowels is where r-intrusion occurs in that dialect. He calls the relevant constraint Final-C, which forbids words from ending in short vowels, although points out that various formulations would also have the desired effect. McCarthy suggests that a number of other languages show effects of a constraint like this, such as the requirement that Arabic noun and verb stems, and Yapese words, must end in a consonant, as well as the Bristol 1 effect; the effect in Tunica (next section) also appears to be related.

10. Details of the use of Bristol [1] are hard to come by; all the references report that it is highly stgmatized and now rare. I assume that this means that, like similar dialectal phenomena like Boston $[r]$, its use is variable, and that therefore it must be productively inserted. However, even if it has become underlying in the dialect in question, due to the assumption of Richness of the Base in OT we still require this same constraint ranking to account for its distribution: we need to assure that any hypothetic input with word-final schwa cannot surface faithfully. 
11. See Prince and Smolensky section 8.3.2 for an attempt to work this out using their peak/margin hierarchies, although they acknowledge that it is only a first attempt. See also Bernhardt and Stemberger (1998) section 4.7.1.3 who suggest that the coda is subject to conflicting requirements that it be a good margin and a good rime. In previous versions of this paper I used a constraint that required moras to be sonorant a la Moren (1999), but this would suggest there is some connection between coda epenthesis possibilities and syllable weight, and I have no evidence for such a correlation.

12. In some cases $/ \mathbf{y} /$ seems to be the unmarked coda nasal (Trigo 1988, see also Bernhardt and Stemberger 1998), and this is sometimes seen in cases of epenthesis. For example, the only singly-linked syllable-final consonants in Buginese (Austronesian; Mills 1975) are $/ \mathrm{y}, ? / \mathrm{j} / \mathrm{y} /$ is epenthesized in subminimal loan words:

$$
\text { "tea" *te, ten (p53.) }
$$

A similar phenomenon is seen in Kaingang reduplication (Brazil; Yip 1992). Trigo argues that the coda velar nasal is a placeless nasal glide, and as we have seen in this paper, similar arguments for Placelessness can be reanalyzed as a result of ranked markedness constraints (see also the Conclusion below).If we retain only Trigo's assumption that this segment is a glide, so that this segment is more sonorous than the [+cons] nasals, it may sometimes be a preferable coda regardless of its Place. However, more research is needed since it is unclear that the velar nasal is always a glide in the relevant cases; for example Frederick Parkinson (p.c.) who has heard Buginese spoken, informs me that it does not seem to be a glide in that language.

13. The choice among the coronals is due to additional phonological factors discussed by Cahill and high ranking of various faithfulness constraints; for example, [d] cannot occur intervocalically except in limited cases that do not allow its appearance at the stem-suffix boundary; other possibilities such as [n] are ruled out by high ranked faithfulness constraints prohibiting insertion of the relevant features.

14. This constraint is obviously contradictory to the unmarkedness of the major Place of glottal stop. (See McCarthy 2001 for a discussion of the need for constraints with opposite requirements.) I assume that this constraint is due to the perceptual difficulty of glottal stop, which for example is probably why glottal stop can only appear in onsets in a language like English. The conflict between the formal unmarkedness of the Place of the glottal and its perceptual markedness accounts for the fact that while glottal stop is relatively unmarked, not all languages have it in their inventory, since they may resolve this conflict in different ways. This is a good example of why implicational relations are not sufficient, or even necessary, evidence for phonological markedness. Not all languages that have coronals have glottals, so implicational relations do not diagnose glottal stop as unmarked, but its phonological behavior shows the other diagnostics of unmarkedness (see note 1), and we are obligated to account for 
this even in the absence of implicational evidence. The existence of a constraint like *? (which may be stated in an oversimplified way here, but some version of which is clearly necessary) for the perceptually problematic glottal stop but not for the perceptually unproblematic coronals accounts for why the markedness relations I propose for coronals and glottals, and reflected in their phonological behavior, are not also reflected in sound system implications. Note that such an approach is likely necessary to account for many other implicational relations, many of which have exceptions and can only be stated as 'tendencies' if we do not use the concept of constraint conflict.

15. See Smolensky 1993, Hironymous 1999 for an analysis of these requirements decomposed into a family of constraints on Alignment of the relevant features; see the latter for additional discussion of the empirical generalization involved as well. As a reviewer points out, once we admit the existence of segment markedness constraints like *?, the appropriate ranking of a $* \mathrm{~h}$ constraint, which probably must exist, could also prevent $[\mathrm{h}]$ being chosen as the epenthetic consonant. But as pointed out in the text, the sonority cline constraints are necessary to pick the appropriate Coronal as epenthetic anyway, so I assume it is this broader generalization that is at work.

16. See Unseth 2002 for additional cases that have been argued to have a default / $\mathrm{t} /$, all of which are similarly restricted to particular morphological situations.

17. Another case that may come to the reader's mind is the insertion of $/ \mathrm{s} / \mathrm{or} / \mathrm{t} / \mathrm{with}$ certain German morphemes. This is sometimes referred to as a 'linking morpheme', but even analyses that do not wish to consider it a morpheme as such must state a purely morphological context for its environment (Wiese 1996:232). Note that unlike cases like Axininca and Odawa, where syllable wellformedness is at least partially responsible for the insertion of the consonant, this epenthetic segment results in longer consonant clusters and thus more marked syllables: eg. Kind $+\mathrm{s}+$ kopf, Wesen $+\mathrm{t}+$ lich.

18. Although Konni may be different from the other cases. In Cahill's analysis, the noun class 1 plural is underlyingly identical to the verbal imperfective suffix; since the relevant alternations occur only with the plural, we appear to need morphological specificity. However, Cahill notes elsewhere that all verb stems end in short vowels underlyingly. Since epenthesis only occurs after (certain) long vowels, it might actually be possible to pursue a purely phonological analysis in this case.

19. McCarthy and Prince's analysis of Axininca invokes Alignment constraints, which are another possible more general way of acheiving certain types of phonology-morphology interaction, but the point remains the same. 
20. In addition to Zoll's examples, a case of $/ \mathrm{n} /$ epenthesis in Swiss German is argued by Ortmann (1998) to be a ghost consonant (although under different theoretical assumptions). He also notes that some speakers of Dutch have /n/-epenthesis at word-clitic boundary. (Booij 1996:227). As in the cases noted in the text, this is found only in a specific morphological environment, and is not the general epenthetic consonant of the language: elsewhere hiatus is resolved by vowel deletion, homorganic glide epenthesis, or glottal stop epenthesis, depending on the vowel (Booij 1995). 